\title{
ИННОВАЦИОННАЯ СТРАТЕГИЯ И РЕФОРМЫ КНР КАК ФАКТОР ЭКОНОМИЧЕСКОГО РОСТА В УСЛОВИЯХ НЕСТАБИЛЬНОСТИ МИРОВОЙ ЭКОНОМИКИ
}

\author{
(C) 2021 Вень Юйчжу \\ Директор строительной компании ООО «Синчжу», \\ внештатный сотрудник международного отдела Shenyang Jianzhu University (KHP) \\ E-mail:wenyuzhu1983@163.com
}

(c) 2021 Аюрзанайн Аюр Биликтоевич

кандидат экономических наук, доцент кафедры «Экономическая теория, мировая экономика, государственное и муниципальное управление»

Восточно-Сибирский государственный университет технологий и управления, Россия, Улан-Удэ

E-mail: ayurza9@yandex.ru

\section{(c) 2021 Дармаева Оксана Александровна}

магистрант кафедры «Экономика, организация и управление производством»

Восточно-Сибирский государственный университет технологий и управления, Россия, Улан-Удэ

E-mail: oksana.smart@yandex.ru

Данная статья посвящена анализу современной ситуации в экономике Китая. В статье проанализировано влияние пандемии коронавирусной инфекции COVID-19 на экономический рост Китая. Особенное внимание уделено изменениям в вопросах формирования инновационной политики и экономическим реформам.

Ключевые слова: Экономика КНР, Китай, современное состояние, ВВП, экономический рост, нестабильность экономики, влияние COVID-19, экономический рост, инновационная политика, инвестиции.

В январе 2020 года в Китае вспыхнула коронавирусная пневмония. Чтобы предотвратить ее распространение, 23 января 2020 года Национальное правительство приняло ограничительные меры в городе Ухань. Общественный транспорт, метро, паромное и междугороднее пассажирское сообщение были приостановлены, аэропорты и вокзалы, выходы временно закрыты. С тех пор, начиная с 25 января, другие 30 провинций и автономных районов приступили к чрезвычайному реагированию на чрезвычайные ситуации в области общественного здравоохранения первого уровня. Транспортный поток сокращается, мероприятия, привлекающие большое количество людей, отменяются, туристические достопримечательности закрываются и т.д. Это сыграло важную роль в борьбе с эпидемией, но эти меры неизбежно оказывают огромное влияние на поведение потребителей и общую экономическую жизнь рынка. Были закрыты отрасли, связанные с массовым потреблением, такие как общественное питание, гостиницы, розничная торговля, туризм, кино, транспорт, досуг и развлечения, а также другие концентрированные отрасли. В обрабатывающей промышленности такие трудоемкие отрасли, как текстильная, швейная, мебельная и бумажная, серьезно страдают от закрытия предприятий и недостаточного предложения сырья [4].

Влияние эпидемии на китайскую экономику. В период вынужденной изоляции населения уровень потребления в стране снизился, а некоторая экономическая активность прекратилась, что привело к росту безработицы. В результате доходы государственного бюджета сократились. С другой стороны, существует также потребность в увеличении расходов: в январе-марте государство инвестировало 137,2 млрд. юаней в здравоохранение и профилактику эпидемий, больницы и первичную медико-санитарную помощь, а также организации здравоохранения.

Вспышка привела к ухудшению макроэкономической ситуации в Китае, где ВВП упал на 6,8\% в период с января по март 2020 года (Таблица 1$)$.

Влияние эпидемий на промышленность. Вспышка коронавируса оказала значитель- 
Таблица 1. ВВП КНР в 2020 году (первый квартал, предварительная оценка) [5]

\begin{tabular}{|l|l|l|}
\hline Показатель & $\begin{array}{l}\text { Абсолютная сумма } \\
\text { (100 тыс. юаней) }\end{array}$ & $\begin{array}{l}\text { Изменение по сравнению } \\
\text { с аналогичным периодом } \\
\text { прошлого года (\%) }\end{array}$ \\
\hline ВВП & 206504743 & $-6,83$ \\
\hline $\begin{array}{l}\text { Добыча сырья, сельское хозяйство, горнодобывающая, } \\
\text { рыбная и лесная промышленность }\end{array}$ & 10186654 & $-3,22$ \\
\hline Промышленное производство и строительство & 73638564 & $-9,61$ \\
\hline Сфера услуг, образование и туризм & 122680453 & $-5,23$ \\
\hline
\end{tabular}

ное влияние на экономическую активность в Китае. С января по февраль прибыль крупных промышленных предприятий упала на 38,3\% в годовом исчислении (в сопоставимых единицах). В январе-марте основные экономические показатели также продолжали снижаться: промышленное производство сократилось на 8,5\%, а строительство-на 17,5\% (табл.4). Коэффициент использования промышленного потенциала в стране составил 67,3\%, что на 8,6\% меньше, чем за аналогичный период прошлого года. Однако, начиная с марта, основные экономические показатели показывают динамику восстановления, масштабы его снижения значительно снизились. В марте уровень производства крупных промышленных предприятий в основном вернулся к уровню аналогичного периода прошлого года. Например, добавленная стоимость крупных промышленных предприятий упала на 1,1\% в годовом исчислении в реальном выражении (13,5\% в январе-феврале).

Хотя традиционная индустрия контактных услуг сильно пострадала, но полагаться на большие данные, облачные вычисления, интернет вещей и новые технологии современной индустрии услуг неуклонно развивается, чтобы удовлетворить основные потребности жизни людей, чтобы обеспечить сильную поддержку, чтобы помочь предприятиям возобновить работу и производство [1]. С января по март сектор услуг по передаче информации, программному обеспечению и информационным технологиям вырос на 13,2\%.

Влияние эпидемии на инвестиции. Когда экономическая активность прекратилась, эпидемия серьезно повлияла на инвестиции в основной капитал: темпы их роста в обрабатывающей промышленности, инфраструктуре и развитии значительно снизились. В январемарте инвестиции в основной капитал страны (без учета фермерских хозяйств) составили 8414,5 млрд. юаней, что на 16,1\% меньше, чем за аналогичный период прошлого года. Но это снижение ниже, чем с января по февраль (когда инвестиции в основной капитал сократились на $24,5 \%)$.

Еще в марте, с дальнейшим усилением государственной политики поддержки экономики, начала проявляться тенденция к возобновлению инвестиций в основной капитал: рост на 6,05\% в месяц. В результате в марте было запущено 11998 новых проектов, что на 9497 больше, чем за предыдущие два месяца. Также выросли показатели возобновления работы строительных предприятий и девелоперских компаний. По состоянию на 9 апреля 2020 года они составляли $82,6 \%$ и $85,6 \%$ соответственно, что на $43,3 \%$ и 37\% выше, чем в конце февраля.

Влияние эпидемии на импорт и экспорт. После вспышки эпидемии в Китае упало не только производство промышленной продукции, но и внешняя торговля. Из-за остановки предприятий, логистического отставания, сроков доставки заказов не до стандарта, сказываются импорт и экспорт. В феврале новые экспортные заказы и показатели импорта составили 28,7\% и 31,9\% соответственно, что на 20\% и 17,1\% меньше, чем в предыдущем месяце. Общая стоимость импорта и экспорта упала на 11\% в годовом исчислении, общая стоимость экспорта упала особенно значительно в годовом исчислении, снизившись на $17 \%$ в годовом исчислении, импорт упал на $4 \%$.

Второе - это влияние эпидемии на экономику провинции Хэйлунцзян. За первые три месяца 2020 года ФРП провинции Хэйлунцзян достиг 240,9 млрд. юаней, что на 8,3\% меньше, чем за аналогичный период прошлого года (в сопоставимых ценах). В то же время, за исключением первичного сектора экономики, эти показатели снизились больше, чем на национальном уровне.

В январе-марте добавленная стоимость крупных промышленных предприятий упала на $8,6 \%$ в годовом исчислении. Самый большой спад произошел в обрабатывающей промышленности-она упала на $16 \%$.

Инвестиции в основной капитал провинции 
упали на 10,9\% в годовом исчислении (январьфевраль-на 27,6\% в годовом исчислении), что ниже общероссийского уровня. Общий объем импорта и экспорта провинции составил 45,22 млрд. юаней, что соответствует аналогичному периоду прошлого года, общий объем розничных продаж потребительских товаров упал на 33,4\% в годовом исчислении.

С января по март 2020 года основные экономические показатели провинции постепенно снижались. С марта они начали набирать обороты, спад спал, порядок производства и условия жизни быстро восстановились, а экономическая активность стабилизировалась.

Экономика провинции в настоящее время в значительной степени восстановилась. По состоянию на май 2020 года возобновили свою деятельность 1265,7 тыс. индивидуальных предприятий с коэффициентом восстановления 80,99\%. Критическая скорость восстановительных работ

В-третьих, контрмеры центрального правительства. Для того чтобы уменьшить экономические потери, вызванные эпидемией, и ускорить возобновление экономической деятельности, различные ведомства китайского правительства приняли ряд мер

Конкретные действия по поддержке производства. После начала эпидемии в провинциях и городах также были приняты меры по поддержке предприятий и организаций. При этом особое внимание на этом уровне уделяется малым и средним предприятиям, в том числе индивидуальным предпринимателям.

Негативное влияние эпидемии на китайскую экономику было наибольшим в первые три месяца 2020 года, а затем становилось все слабее и слабее. Это результат позитивных мер, принятых центральным правительством и местными властями. Опрос, проведенный накануне 2021 года, показал, что 74,2\% предпринимателей ответили «очень уверенно» или «относительно уверенно» в отношении улучшения перспектив для ведения бизнеса, в том числе производственного. Связанного с инновациями. Это говорит о том, что негативное влияние новой коронавирусной пневмонии на китайскую экономику временно ограничено, в то время как общие условия, поддерживающие качественное и здоровое функционирование китайской экономики, остаются неизменными, гарантируя, что Китай играет важную роль в глобальной цепочке поставок товаров и услуг.
Мы обнаружили, что в нестабильных ситуациях структура общественной жизни существенно изменилась - многие ключевые институты либо перестали работать, либо провели масштабную реконструкцию, чтобы выжить в новых условиях. Такая ситуация угрожает жизни системы, и необходимо принимать позитивные меры для ее улучшения.

За последние несколько десятилетий заявленные Китаем цели в области экономического развития неуклонно достигались, поэтому можно предвидеть, что Китай обладает потенциалом стать одним из мировых инновационных лидеров.

В течение следующих 15 лет Китай должен решить эти задачи в наиболее важных областях науки и техники:

1) освоение ключевых технологий производства оборудования и информационных отраслей, имеющих важное значение для национальной конкурентоспособности, с тем чтобы технологический производственный потенциал и информационные отрасли могли выйти на мировой уровень;

2) выход ведущего мирового аграрного сектора страны с научно-техническим потенциалом для повышения потенциала сельскохозяйственного производства, а также обеспечения национальной продовольственной безопасности;

3) достижение энергетического развития, энергосбережения и сокращения выбросов, чистой энергетики и других аспектов технологических прорывов, содействие оптимизации энергетической структуры, достижение мирового уровня энергопотребления на единицу промышленной продукции;

4) создать технологическую модель для ключевых отраслей промышленности и Городского Развития, а также поддержать НДт в построении ресурсосберегающего и экологически чистого общества.;

5) значительно усилить профилактику и лечение СПИДа, гепатита и других основных заболеваний, добиться прорывов в производстве новых лекарственных средств и ключевых медицинских изделий, создать потенциал индустриализации;

6) удовлетворять потребности в разработке современного оружия и связанных с ним информационных технологий и обеспечивать поддержку наилучших доступных технологий для обеспечения национальной безопасности; 
7) создать команду из ученых мирового уровня; определить базовые направления перспективных направлений исследований с учетом международной конкуренции.

8) многие научно-исследовательские институты, университеты и исследовательские центры мирового уровня были созданы для того, чтобы конкурировать в глобальном масштабе и формировать национальную инновационную систему с китайскими особенностями. Ожидается, что к 2020 году общие расходы Китая на НИОКР составят не менее 2,50\% валового внутреннего продукта.

Правительство КНР в значительной степени управляет инновационной отраслью посредством применения определенных регулирующих инструментов налоговой политики: установление льгот, выделение бюджетных субсидий, продвижение государственного финансирования инновационных процессов (гранты и государственные заказы).

Важно то, что вовремя в 2018 году Правительство КНР утвердило «Положение об обязательном использовании части прибыли для создания и выпуска инновационной продукции», это фактически подтвердило «обязательную» инновационную политику для всех производственных предприятий страны.

В этой связи можно выделить следующие руководящие принципы государственного управления:

1. Разработать стратегию для определения основных приоритетов инноваций и развития МСП.

2. Координировать деятельность сектора МСП.

3. Льготная налоговая политика для МСП.

4. Оказывать финансовую поддержку МСП.

5. Информационное, консультационное и бизнес-сопровождение.

6. Создавать бизнес-инкубаторы.

7. Содействовать финансированию инновационных компаний путем создания венчурных фондов.

Данный организационный механизм можно назвать системой (см. рис. 1), направленной на адаптацию технологического процесса к новым условиям и повышения эффективности в новой среде [3].

Современная структура управления инновациями в КНР является трехуровневой, в которой главное место занимают государственные и частные фонды. Таким образом следует выделять три уровня данной системы:

1) национальный компетентный орган;

2) консультационные, координационные и финансовые институты;

3) Исполнительная организация.

Данную структуру следует представить на рисунке 2 .

Можно говорить о том, что выстроенная в настоящее время Национальная структура управления инновациями и развитием в Китае является максимально иерархичной, с четко вы-

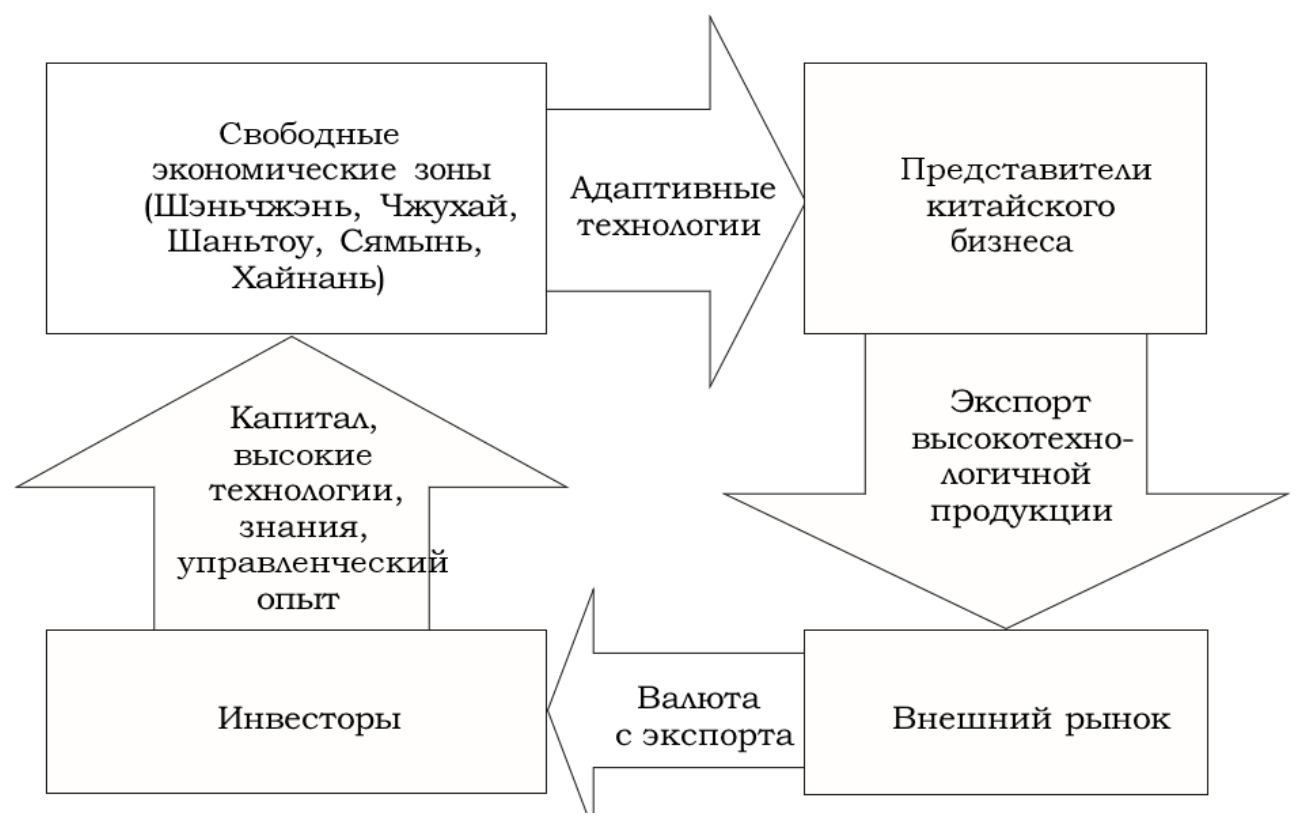

Рисунок 1. Система формирования инновационного потенциала Китая 


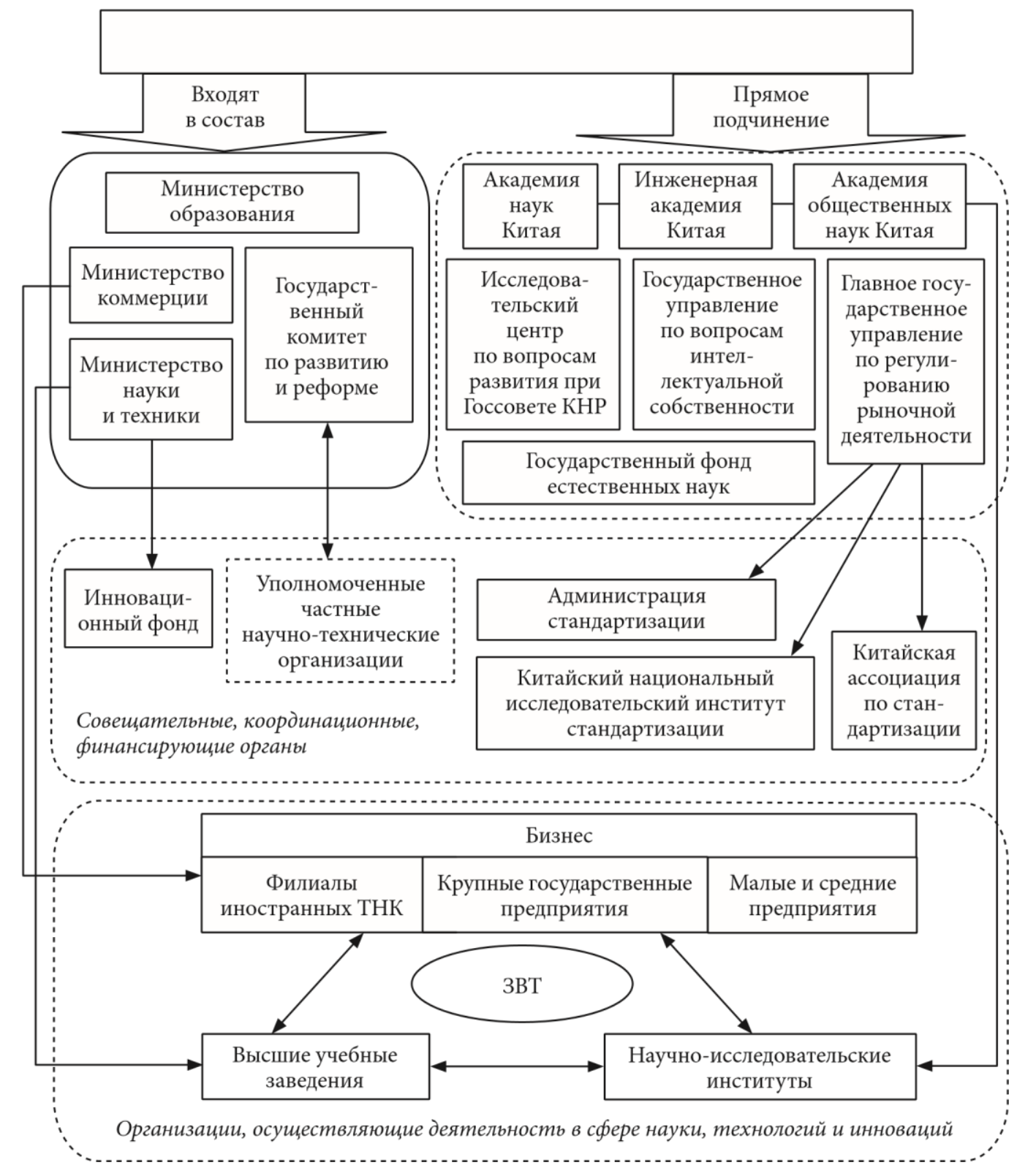

Рисунок 2. Национальная структура управления инновациями и развитием в Китае [2]. Примечание: 3ВТ - это парк высоких технологий

деленными по функционалу институтами развития. При этом цели технологических исследований соответствуют Национальному плану исследований и разработок.

Политику в области инноваций во многом определяет Министерство промышленности и информационных технологий, которое отвечает за разработку и продвижение инновационных проектов, формирование зон высоких технологий и строительство с последующим финансированием бизнес-инкубаторов. На региональном уровне контролем и мониторингом за соответствие направлениям инновационной политики осуществляют региональные отделения Мини- стерства. При этом Министерство науки и технологий курирует национальный департамент науки и технологий и определяет финансирование национального плана развития технологий в рамках текущей деятельности.

Таким образом, следует говорить о том, что инновационная система КНР в современных условиях оказалось способной противостоять новым вызовам социально-экономической реальности и произвела ряд важных институциональных изменений, которые позволили адаптировать систему с организационной точки зрения. 


\section{Библиографический список}

1. Аюрзанайн А.Б. Развитие финансовых институтов как фактор экономического роста в условиях глобализации: монография.-Вост.-Сиб. гос. ун-т технологий и упр., 2013.

2. Василенок В. Л., Гуляева К. С., Коробова Е. А. Об инновационном развитии экономики Российской Федерации и Китайской народной республики //Научный журнал НИУ ИТМО. Серия «Экономика и экологический менеджмент».-2019.- № . 2 .

3. Герцик Ю.Г. Анализ опыта России и Китая в реализации кластерной политики и совместных инновационных проектов //В центре экономики. - 2020.- № . 3.

4. Короткевич А. И., Цзымин С., Тяньхуа Ц. Инвестиционно-инновационные стратегии и кластерный подход в промышленности Китайской Народной Республики в контексте реализации стратегического управления. 2020.

5. Официальный сайт Статуправления KHP. URL: http://www.stats.gov.cn 